\title{
A theoretical study on the dimers of aminoacrylonitrile (3-amino-2-propenenitrile), a compound of astrochemical interest
}

\author{
Otilia Mó, ${ }^{a}$ Manuel Yáñez, ${ }^{a^{*}}$ and Jean-Claude Guillemin ${ }^{b}$ \\ ${ }^{a}$ Departamento de Química, C-9 Universidad Autónoma de Madrid, Cantoblanco, \\ 28049-Madrid, Spain \\ ${ }^{b}$ Laboratoire de Synthèse et Activation de Biomolécules, UMR CNRS 6052, ENSCR, Institut de \\ Chimie de Rennes, 35700 Rennes, France \\ E-mail: manuel.yanez@uam.es

\section{Dedicated to Professor José Elguero and Pedro Molina on the occasion of their $70^{\text {th }}$ and $60^{\text {th }}$ birthdays, respectively}

(received 22 Dec 04; accepted 01 Apr 05; published on the web 07 Apr 05)

\begin{abstract}
The structure, bonding, and relative stability of the dimers of aminoacrylonitrile were investigated through the use of high level density functional theory (DFT) calculations. Geometries and harmonic vibrational frequencies were obtained at the B3LYP/6-311+G(d,p) level. Final energies were estimated by means of B3LYP/6-311+G(3df,2pd) single point calculations. The aminoacrylonitrile dimers can be classified attending to the nature of the interacting monomers as $\boldsymbol{E} \boldsymbol{E}$-, $\boldsymbol{E Z}$ - or $\boldsymbol{Z Z}$-types. The primary factor controlling the relative stability of these dimers is the intrinsic stability of the two monomers combining in the complex. Since the $\mathbf{Z}$ monomer is predicted to be $c a .8 \mathrm{~kJ} \mathrm{~mol}^{-1}$ more stable than the $\boldsymbol{E}$ monomer, the $\mathbf{Z Z}$ type dimers are more stable than the $\boldsymbol{E Z}$ ones, and these are more stable than the $\boldsymbol{E} \boldsymbol{E}$ ones. Irrespective of the composition of the dimer, the most stable complexes correspond to those in which the HB acceptor is the cyano group. The global minimum, ZZ1, benefits not only from the enhanced stability of the $\boldsymbol{Z}$ monomer but also from non-negligible cooperative effects. The estimated dimerization enthalpy for aminoacrylonitrile $\left(55.8 \mathrm{~kJ} \mathrm{~mol}^{-1}\right)$ is only slightly smaller than those of carboxylic acids, such as formic, acetic or trifluoroacetic acid. Hence, the aminoacrylonitrile vapors should contain a significant amount of dimers.
\end{abstract}

Keywords: Aminoacrylonitrile (3-Amino-2-propenenitrile), hydrogen-bonded dimers, cooperative effects, density functional theory calculations 


\section{Introduction}

Aminoacrylonitrile 1 (3-amino-2-propenenitrile) is a kinetically stable enamine of great astrochemical interest for its possible presence in the interstellar medium, the comets, and the atmospheres of planets, including the primitive Earth. The formation of this compound in the aforementioned media is likely associated with the reaction of cyanoacetylene $2(\mathrm{HC} \equiv \mathrm{C}-\mathrm{C} \equiv \mathrm{N})$ and ammonia. The former is a compound observed in the interstellar medium, ${ }^{1,2}$ in comets, ${ }^{3}$ in the atmosphere of Titan ${ }^{4,5}$ and in numerous laboratory simulations of planetary atmospheres, ${ }^{6,7}$ and has often been proposed as a key- starting material ${ }^{8,9}$ for the formation of more complex derivatives in interstellar space and on the primitive Earth. ${ }^{10}$ Ammonia, on the other hand, has been detected in many places in the Universe. ${ }^{11,12}$

The reaction of ammonia with cyanoacetylene 2 in a solvent ${ }^{13}$ or in gaseous phase ${ }^{14}$ yields a mixture of $\mathbf{Z}$ - and $\mathbf{E}$-aminoacrylonitrile $\mathbf{1}$ (3-amino-2-propenenitrile). The $\mathbf{Z} / \mathbf{E}$ ratio in the reaction mixture is about 1 (unity) but rises to about 20 after distillation in vacuo. ${ }^{13}$

The reasons behind the enhanced stability of conformer $\mathbf{Z}$ have been discussed in a recent Paper, ${ }^{15}$ in which the infrared spectra of compound $\mathbf{1}$, both in the gas and the condensed phases, were analyzed.

Aminoacrylonitrile can easily yield dimers in the gas-phase, because it can behave simultaneously as a hydrogen-bond (HB) donor, through its $\mathrm{NH}_{2}$ group, and as a $\mathrm{HB}$ acceptor, through either its $\mathrm{C} \equiv \mathrm{N}$ or amino group. It is well established that systems that may behave simultaneously as HB donors and acceptors usually yield vapors characterized by the presence of large amounts of associated species. ${ }^{16}$ A paradigmatic example is provided by carboxylic acids, where the extent of dimerization is very large so that, for example, saturated acetic acid vapor contains about $50 \%$ of dimers at its normal boiling point. ${ }^{17}$ Hence, although ammonia itself does not hydrogen-bond well because it is a very weak $\mathrm{HB}$ donor, ${ }^{18}$ the amino group of aminoacrylonitrile, as we shall show later, can form HB's in which the cyano group of a different monomer behaves as a HB acceptor. Therefore, one of the aims of this paper is to analyze the structure and relative stability of the different dimers that can be formed between the two conformers of aminoacrylonitrile, by using high-level density functional theory (DFT) calculations. This implies a full characterization of the intermolecular HB's and analysis of possible non-pairwise effects in the stability of the different dimers. In fact, since each monomer may behave simultaneously as an HB- donor and acceptor, some of the local minima of the potential energy surface (PES) will have a cyclic structure, that usually enhances the presence of cooperativity effects. Elguero et al. ${ }^{19-25}$ have paid particular attention to the role of cooperativity in hydrogen bonding in water, alcohol, and hydrogen peroxide complexes. Importantly, it has been shown that although cooperativity is usually observed in trimers or $n$-mers $(n>3)$, it can also be found in cyclic dimers, which explains for example part of the strong interaction existing between two monomers of phosphinic acid derivatives. ${ }^{23}$ 


\section{Computational details}

The geometries of the different dimers of aminoacrylonitrile were optimized at the B3LYP/6$311+\mathrm{G}(\mathrm{d}, \mathrm{p})$ level of theory. The B3LYP approach includes Becke's three-parameter non-local hybrid exchange potential ${ }^{26}$ and the non-local correlation functional of Lee, Yang and Parr. ${ }^{27}$

Harmonic vibrational frequencies were obtained at the same level of theory to classify the stationary points as local minima, and to estimate the corresponding zero point energies (ZPE), thermal corrections to the free energy, and entropy. In order to gain reliable dimerization energies, the final energies of the monomers and dimers were obtained by B3LYP/6$311+\mathrm{G}(3 \mathrm{df}, 2 \mathrm{pd})$ single point calculations carried out on the B3LYP/6-311+G(d,p) optimized geometries. This theoretical approach has been shown to be quite reliable for describing hydrogen bonded complexes, ${ }^{28-30}$ yielding dimerization energies in close agreement with values obtained through the use of high-level $a b$ initio calculations and with the experimental values when these are available. All these calculations were carried out with the Gaussian-98 and Gaussian-03 series of programs. ${ }^{31,32}$

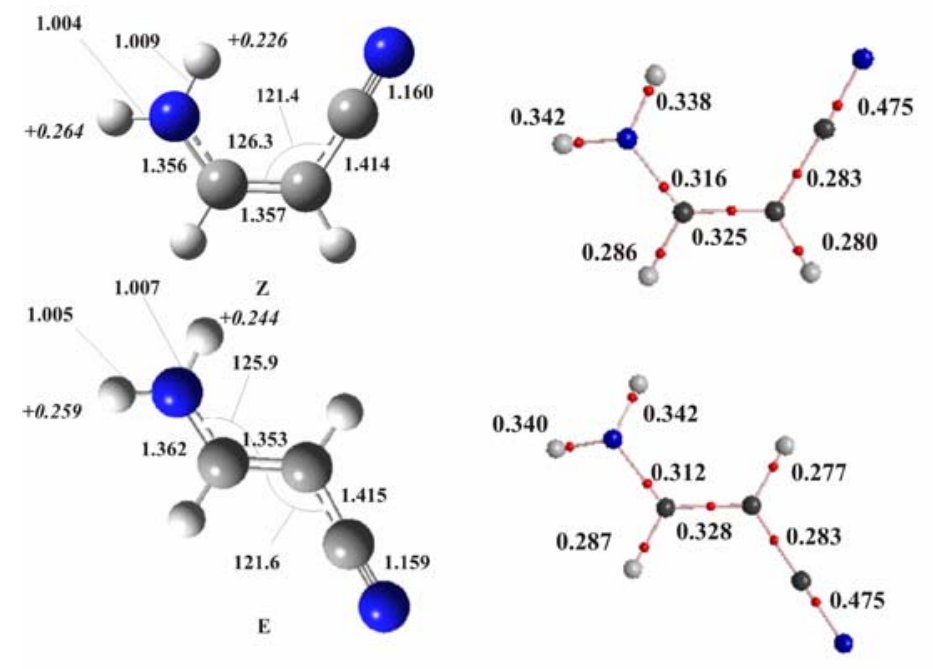

Figure 1. B3LYP/6-311+G(d,p) optimized geometries and molecular graphs of the $\boldsymbol{E}$ and $\boldsymbol{Z}$ stereoisomers of aminoacrylonitrile. Bond lengths are in $\AA$, bond angles are in degrees, and charge densities at the bond critical points (red dots) in a.u.

To investigate the bonding features of the most stable dimers we used the atoms in molecules (AIM) theory, ${ }^{33}$ which is based on a topological analysis of the electron charge density $\rho(\mathbf{r})$ and its Laplacian, $\nabla^{2} \rho(\mathbf{r})$. Using this formalism we located the bond critical points (i.e., points where $\rho(\mathbf{r})$ is minimum along the bond path and maximum in the other two directions) because the values of charge density at these points provide useful information on the strength of the linkages. Indeed, a decrease in the charge density at a given bcp should be reflected in a weakening of the bond, and therefore in an increase of its bond-length, and a red-shift of its 
stretching frequency. Conversely, an increase in charge density at the bcp is associated with bond reinforcement, reflected in shorter bond-lengths and higher stretching frequencies. The location of ring critical points also permits ratification of the existence of cyclic structures. These analyses were performed with the AIMPAC suite of programs. ${ }^{34}$

\section{Results and Discussion}

As indicated in the Introduction, aminoacrylonitrile has two stereoisomers $\mathbf{E}$ and $\mathbf{Z}$ (see Figure 1). At the B3LYP/6-311+G(3df,2pd) level the $\mathbf{Z}$ isomer is estimated to be $7.4 \mathrm{~kJ} \mathrm{~mol}^{-1}$ more stable than the $\mathbf{E}$ one, in very good agreement with previous estimates $\left(8.3 \mathrm{~kJ} \mathrm{~mol}^{-1}\right)$ obtained through the use of the G2-theory. ${ }^{15}$ Therefore, in principle, it would be possible to find three series of dimers, corresponding to the $\mathbf{E E}, \mathbf{E Z}$ and $\mathbf{Z Z}$ combinations. On the other hand, within each of these series, the association between the two monomers can present different arrangements depending on the nature (cyano or amino) of the proton-accepting group.

Hereafter, the dimers will be named by identifying the nature of the isomers involved followed by a number which indicates their relative stabilities in terms of free energies. Hence EE1 will designate the most stable dimer in the gas phase formed by the interaction of two $\mathbf{E}$ stereoisomers.

\section{Geometries}

The optimized geometries of the different local minima in which the proton-accepting group is the amino group of one of the monomers are shown in Figure 2. It is observed that in all these complexes, the two interacting molecules lie on planes which are almost perpendicular to each other to favor the interaction of the proton donor with the lone pair of the amino group of the HB acceptor. Complex ZZ3 is the only exception. In this the dihedral angle between the planes containing the $\mathrm{HB}$ donor and the $\mathrm{HB}$ acceptor is only $48^{\circ}$ in order to favor the existence of a $\mathrm{HB}$ between a $\mathrm{C}-\mathrm{H}$ group of the $\mathrm{HB}$ donor and the $-\mathrm{CN}$ group of the $\mathrm{HB}$ acceptor, clearly shown in the corresponding molecular graph. The situation is less systematic when the HB acceptor is the cyano group (Figure 3).

Only three complexes, namely EZ1, EZ3 and ZZ1 are strictly planar, in all other cases the planes that contain the HB- donor monomer and the HB- acceptor monomer form different dihedral angles that are shown in the Figure. In the EE4 complex both molecules lie in parallel planes, and the dimer has $\mathrm{C}_{\mathrm{i}}$ symmetry. Also, the global minimum of the PES, ZZZ1 has $\mathrm{C}_{\mathrm{i}}$ symmetry. 

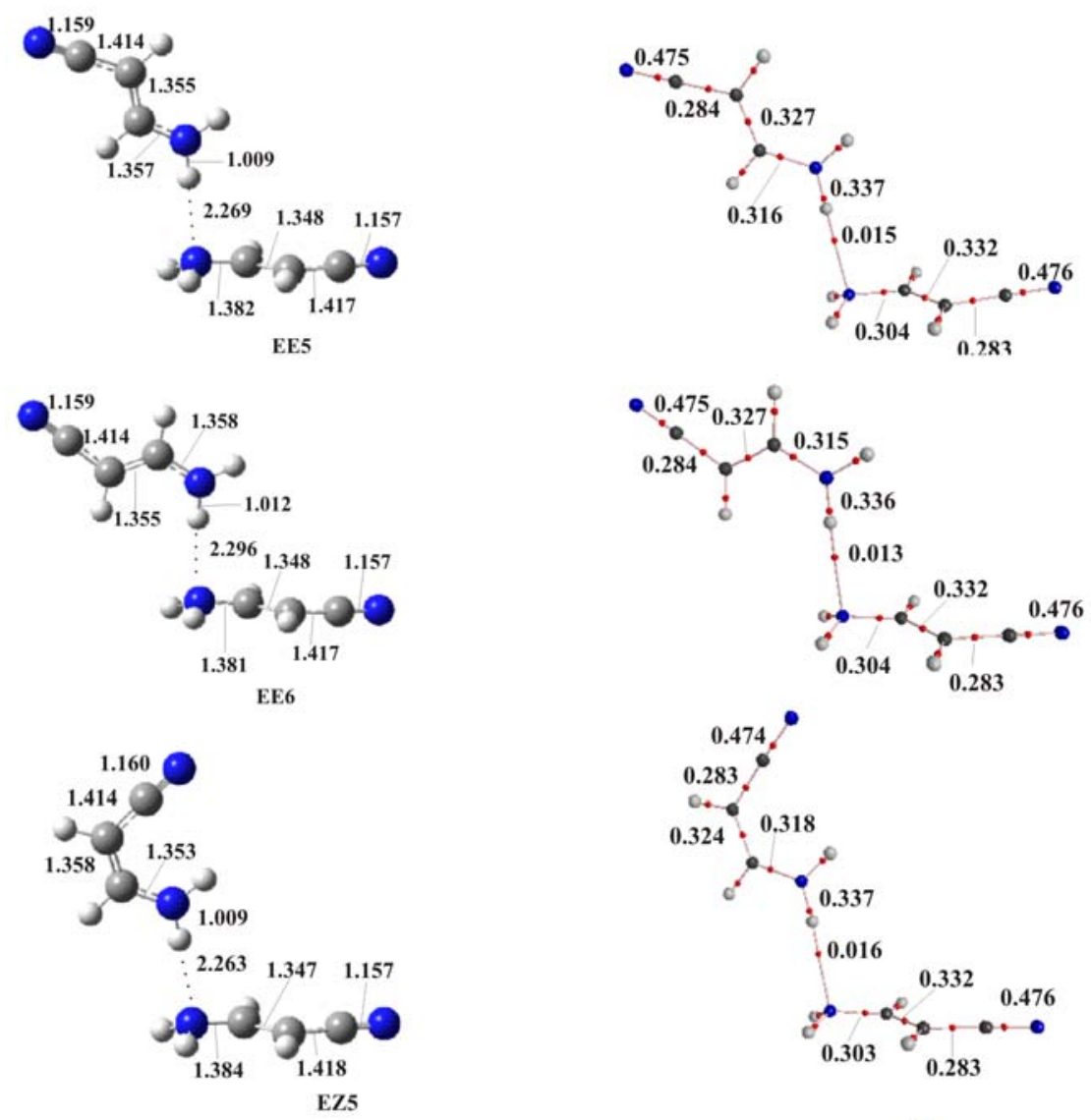

$0.324 \cdot 0.318$

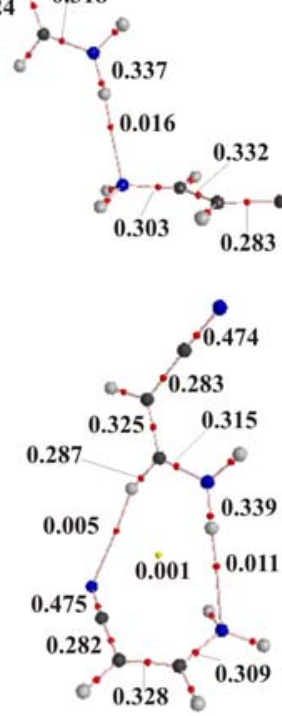

Figure 2. B3LYP/6-311+G(d,p) optimized geometries and molecular graphs of aminoacrylonitrile dimers in which the HB acceptor is the amino group. Bond lengths are in $\AA$, bond angles are in degrees, and charge densities at the bond critical points (red dots) in a.u. 

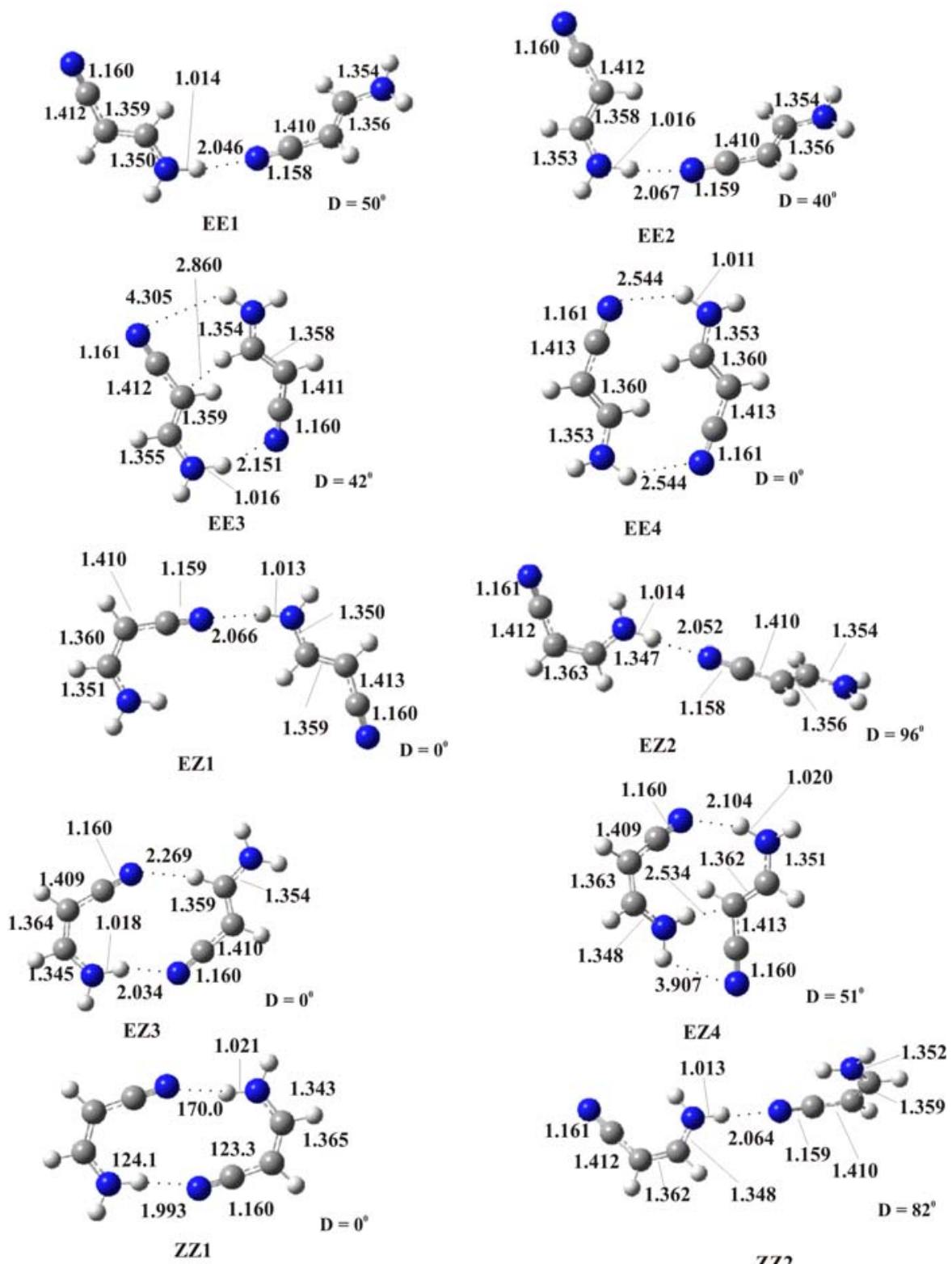

Figure 3. B3LYP/6-311+G(d,p) optimized geometries of aminoacrylonitrile dimers in which the HB acceptor is the cyano group. Bond lengths are in $\AA$, bond angles are in degrees.

\section{Relative stabilities and binding energies} Amino group as $\mathrm{HB}$ acceptor

The total energies, free energies, relative enthalpies, and relative free energies of the species investigated are summarized in Table 1. 
Table 1. Total energy (E, hartrees), zero point energy (ZPE, hartrees), entropy ( $\mathrm{S}$, cal mol ${ }^{-1} \mathrm{~K}^{-1}$ ), free energy $\left(\mathrm{G}\right.$, hartrees), relative enthalpy $\left(\Delta \mathrm{H}, \mathrm{kJ} \mathrm{mol}^{-1}\right)$, relative free energy $\left(\Delta \mathrm{G}, \mathrm{kJ} \mathrm{mol}^{-1}\right)$, and binding energy $\left(\mathrm{BE}, \mathrm{kJ} \mathrm{mol}^{-1}\right)$

\begin{tabular}{llllllll}
\hline & E & ZPE & S & G & $\Delta H$ & $\Delta G$ & BE \\
\hline Monomers & & & & & & & \\
\hline E & -226.285956 & 0.068562 & 72.961 & -226.246212 & 7.4 & 9.2 & - \\
Z & -226.288850 & 0.068765 & 74.497 & -226.249728 & 0.0 & 0.0 & - \\
Dimers & & & & & & & \\
EE1 $^{\mathbf{a}}$ & -452.585148 & 0.136912 & 124.499 & -452.493183 & 34.7 & 16.5 & -34.7 \\
EE2 $^{\mathbf{a}}$ & -452.584682 & 0.136999 & 123.655 & -452.492268 & 36.1 & 18.9 & -33.5 \\
EE3 $^{\mathbf{a}}$ & -452.585130 & 0.137791 & 114.948 & -452.488376 & 35.4 & 29.1 & -34.7 \\
EE4 $^{\mathbf{a}}$ & -452.586396 & 0.138313 & 111.842 & -452.487932 & 32.7 & 30.3 & -38.0 \\
EE5 $^{\mathbf{b}}$ & -452.575135 & 0.137402 & 122.439 & -452.482045 & 61.4 & 45.7 & -8.5 \\
EE6 $^{\mathbf{b}}$ & -452.575107 & 0.137341 & 122.664 & -452.423853 & 61.4 & 45.5 & -8.4 \\
EZ1 $^{\mathbf{a}}$ & -452.587150 & 0.137239 & 125.708 & -452.495607 & 29.9 & 10.1 & -32.4 \\
EZ2 $^{\mathbf{a}}$ & -452.587388 & 0.137213 & 124.253 & -452.495108 & 29.4 & 11.4 & -33.0 \\
EZ3 $^{\mathbf{a}}$ & -452.591383 & 0.137718 & 114.511 & -452.494433 & 19.0 & 13.2 & -43.5 \\
EZ4 $^{\mathbf{a}}$ & -452.588829 & 0.138221 & 112.884 & -452.490982 & 26.0 & 22.3 & -36.8 \\
EZ5 $^{\mathbf{b}}$ & -452.577168 & 0.137754 & 121.459 & -452.483446 & 56.5 & 42.0 & -6.2 \\
ZZ1 $^{\mathbf{a}}$ & -452.598954 & 0.138814 & 109.873 & -452.499461 & 0.0 & 0.0 & -55.8 \\
ZZ2 $^{\mathbf{a}}$ & -452.589430 & 0.137665 & 122.364 & -452.496083 & 24.4 & 8.9 & -30.8 \\
ZZ3 $^{\mathbf{b}}$ & -452.581806 & 0.137841 & 120.025 & -452.487343 & 44.5 & 31.8 & -10.8 \\
\hline & & & & & & &
\end{tabular}

${ }^{a}$ Dimers in which the HB acceptor is the amino group.

${ }^{b}$ Dimers in which the HB is the cyano group.

We shall start our analysis with the dimers in which the proton-accepting group is the amino group of one of the monomers. The first conspicuous fact from Table 1 is that these dimers, namely EE5, EE6, EZ5 and ZZ3 are much less stable, both in terms of enthalpies and free energies, than those in which the HB acceptor is the cyano group. This can be considered, in principle, an unexpected result if one takes into account the fact that, in general, an amino group should yield stronger HBs than a cyano group when the proton donor is the same. At the level of theory used in this work, the $\mathrm{FH} \cdots \mathrm{NH}_{3} \mathrm{HB}$ is found to be $10.5 \mathrm{~kJ} \mathrm{~mol}^{-1}$ stronger than the $\mathrm{FH} \cdots \mathrm{NCH}$ HB. It must be noted, however, that - as explained in ref. 15- the amino group of aminoacrylonitrile is strongly conjugated with the $\pi$-system, in particular with the $\mathrm{C}=\mathrm{C}$ bond. This conjugation is clearly reflected in the planarity of this group in both the E- and the Zisomers. Therefore, the amino group of aminoacrylonitrile must be a much poorer electron donor than is a non-conjugated amino group and accordingly a poorer HB acceptor, which explains why the dimers in which the amino is the HB- acceptor are the least stable of the PES. In this respect it is worth noting that the amino group that behaves as HB acceptor in EE5, EE6, EZ5 
and ZZ3 complexes, becomes slightly pyramidalized, the sum of the angles around the nitrogen being $c a .345^{\circ}$ instead of $360^{\circ}$ which would define a planar group. This is reflected in the lengthening of the $\mathrm{C}-\mathrm{NH}_{2}$ bond and shortening of the $\mathrm{C}=\mathrm{C}$ linkage of the $\mathrm{HB}$ acceptor (Compare Figs. 1 and 2). Consistently, on going from the isolated monomer to the dimer, the charge density at the $\mathrm{C}-\mathrm{NH}_{2}$ bcp decreases, and its stretching frequency appears red-shifted by $33 \mathrm{~cm}^{-1}$, while that at the $\mathrm{C}=\mathrm{C}$ bcp increases and its stretching frequency is $5 \mathrm{~cm}^{-1}$ blue-shifted. The fact that the amino group of aminoacrylonitrile is not a good hydrogen-bond acceptor together with the fact that amino groups are not very good HB donors either, ${ }^{18}$ results in binding energies (See Table 1) which are never greater than $11 \mathrm{~kJ} \mathrm{~mol}^{-1}$ for this kind of complexes.

It can also be observed that no stationary points have been found in which the HB acceptor is the amino group of the $\mathbf{Z}$ isomer. All attempts to obtain $\mathbf{E Z}$ dimers in which the amino group of the $\mathbf{Z}$ monomer behaves as a HB acceptor collapsed to the most stable of these complexes, namely EZ1. Thus, the only EZ-type stationary point with the amino group behaving as HB acceptor that has been located, EZ5, corresponds to a dimer in which the proton donor is the $\mathbf{Z}$ monomer, and the proton acceptor the $\mathbf{E}$ monomer. Similarly, all attempts to obtain $\mathbf{Z Z}$ dimers in which the HB acceptor is the amino group of one of the monomers yield only one stationary point, ZZ3.

\section{The Cyano group as an HB acceptor}

We have located ten different stationary points in which the HB acceptor is systematically the cyano group of one of the monomers. Four of these local minima are EE-type complexes, four are of the EZ-type, and two are ZZ-type.

The primary factor controlling the relative stability of these dimers is the intrinsic stability of the two monomers interacting in the complex. Hence, the ZZ-type dimers are more stable than the EZ ones, and these more stable than the EE ones.

Within the EE-type complexes we can distinguish those in which one of the monomers behaves exclusively as an HB donor and the other as an HB acceptor, namely EE1 and EE2, and those (EE3 and EE4) in which each monomer behaves simultaneously as an HB donor and HB acceptor. It is interesting to note that the latter are the most stable ones in terms of enthalpies, but not in terms of free energies, because they are entropically disfavored owing to their cyclic nature. The same situation is observed as far as EZ-type complexes are concerned. The cyclic dimers EZ3 and EZ4 are the most stable in terms of enthalpies but not in terms of free energies. The situation is different within the $\mathbf{Z Z}$-series, because the $\mathrm{C}_{\mathrm{i}}$ cyclic dimer, $\mathbf{Z Z 1}$, although entropically disfavored, represents the global minimum of PES both in terms of enthalpies and free energies.

It is important to emphasize that the dimerization energy involved in the formation of the $\mathbf{Z Z 1}$ dimer is of the same order of magnitude as those found for carboxylic acids. In fact, our calculated value is only $7 \mathrm{~kJ} \mathrm{~mol}^{-1}$ smaller than the association energy of formic acid and $3 \mathrm{~kJ}$ $\mathrm{mol}^{-1}$ smaller than that of trifluoroacetic acid. This very likely would implies that the aminoacrylonitrile vapors should contain a significant amount of dimers, as is the case for 
carboxylic acids. Taking into account the fact that the boiling point of this compound is $63^{\circ} \mathrm{C}$ at 0.1 mbar, ${ }^{15}$ we have estimated the equilibrium distribution of the different dimers at $350 \mathrm{~K}$, by using the relative free energies reported in Table 1 , and conclude that at this temperature the ratio of dimers in the vapor of aminoacrylonitrile should be: ZZ1 (90.2\%), ZZ2 (4.2\%), EZ1 (2.8\%), EZ2 (1.8\%) and EZ3 (1\%).

\section{Bonding characteristics}

We start our analysis with complexes in which the HB acceptor is an amino group. A cursory examination of Figure 2 seems to indicate that the HB in EE5 dimer is stronger than in EE6. Actually, the $\mathrm{NH} \cdots \mathrm{N}$ distance in EE5 is shorter than in EE6 and the charge density at the bcp is greater. Consistently, the red-shifting of the N-H stretching frequencies of the HB donor is also larger in the former than in the latter (See Table 2). This can easily be explained if one takes into account the fact that EE5 and EE6 differ in the amino hydrogen involved in the HB. In the former, the amino hydrogen is cis- with respect to the neighboring $\mathrm{C}-\mathrm{H}$ group while in the latter the amino hydrogen is trans- to this group, and the net charges of these hydrogens in isomer $\mathbf{E}$ (see Figure 1), show that the former is more acidic than the latter. For the same reason, the HB in complex EE1 is also slightly stronger than that in EE2 dimer, in terms of bond distances (See Figure 3), charge densities at the bcp (see Figure 4) and frequency shifts (see Table 2).

Table 2. Stretching frequencies $\left(\mathrm{cm}^{-1}\right)$ of the $\mathrm{NH}_{2}$ group of the hydrogen-bond donor in aminoacrylonitrile dimers. The two monomers are included for the sake of comparison

\begin{tabular}{ccc}
\hline System & $\mathrm{NH}_{2}$ asymm. stretch & $\mathrm{NH}_{2}$ symm. Stretch \\
\hline E & $3724(3464)^{\mathrm{a}}$ & $3606(3352)^{\mathrm{a}}$ \\
$\mathbf{Z}$ & $3733(3468)^{\mathrm{a}}(3562.5)^{\mathrm{b}}$ & $3598(3357)^{\mathrm{a}}(3437.3)^{\mathrm{b}}$ \\
EE1 & 3680 & 3500 \\
EE2 & 3708 & 3481 \\
EE3 & 3687 & 3492 \\
EE4 & 3673 & 3557 \\
EE5 & 3691 & 3547 \\
EZ1 & 3711 & 3539 \\
EZ2 & 3684 & 3513 \\
EZ3 & 3662 & 3502 \\
EZ4 & $3697^{\mathrm{c}}$ & $3454^{\mathrm{d}}$ \\
EZ5 & 3687 & 3479 \\
ZZ1 & 3674 & 3543 \\
ZZ2 & 3664 & 3511 \\
ZZ3 & $3413^{\mathrm{e}}$ & $3395^{\mathrm{f}}$ \\
\hline
\end{tabular}

${ }^{a}$ Experimental values in the condensed phase taken from ref. $15 .{ }^{b}$ Experimental values in the gas phase taken from ref. 15. ${ }^{\mathrm{c}}$ The N-H stretch of the bond not involved in the HB. 
${ }^{d}$ The N-H stretch of the bond involved in the HB. ${ }^{e}$ In-phase combination of the N-H stretch of the two N-H donors. ${ }^{f}$ Out-of-phase combination of the N-H stretch of the two N-H donors.

The molecular graphs shown in Fig. 4 for complexes in which the HB acceptor is the cyano group show that for some complexes other weak interactions appear, besides the intermolecular HB's.
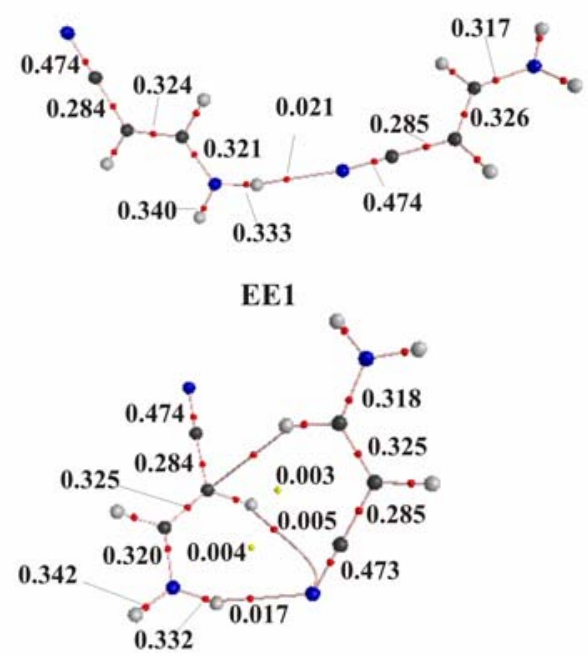

EE3
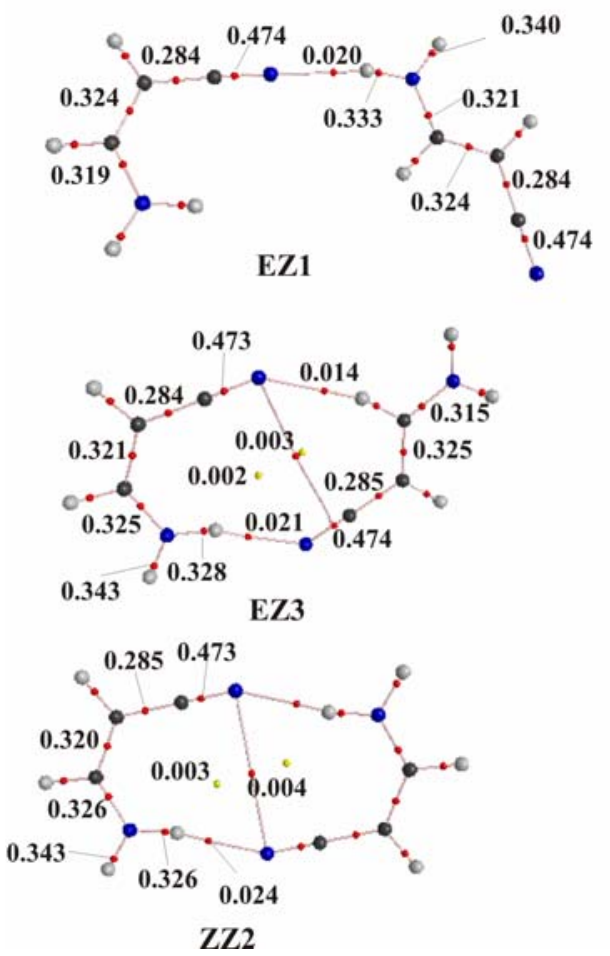

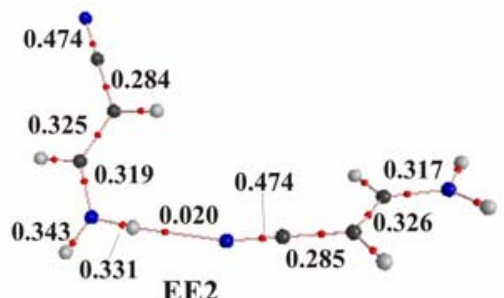

EE2

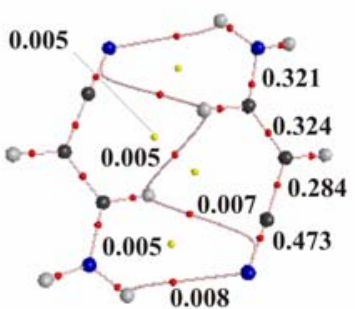

EE4
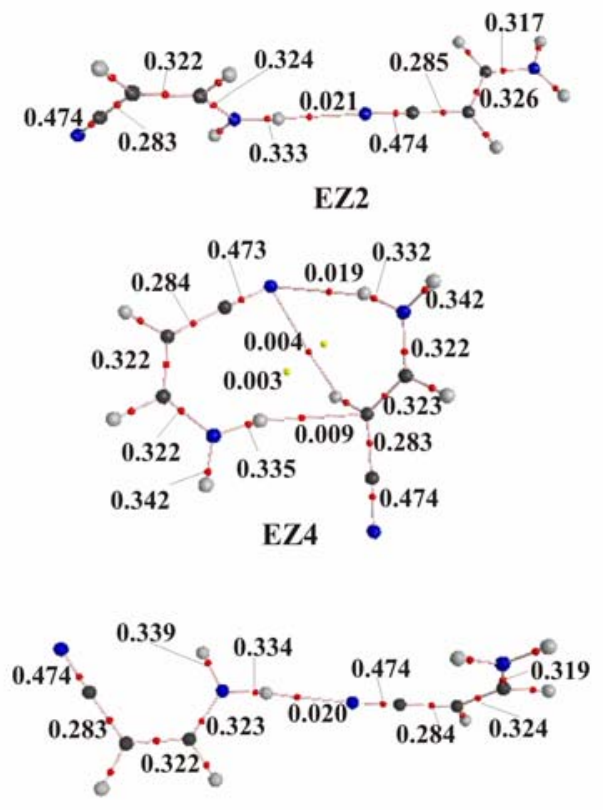

ZZ1

Figure 4. Molecular graphs of aminoacrylonitrile dimers in which the HB acceptor is the cyano group. Charge densities at the bond-critical points (red dots) and at the ring-critical points (yellow dots) are in a.u. 
A paradigmatic example is the complex EE4, which has bond paths between the $\mathrm{H}$ of the methylene group of one monomer and the $\mathrm{C} \equiv \mathrm{N}$ bond of the other. A second-order NBO analysis $^{34}$ actually shows the existence of an interaction between the $\sigma_{\mathrm{CH}}$ bonding orbital of one of the sub-units and the $\pi^{*} \mathrm{CN}$ antibonding orbital of the other. A similar interaction is found in both EE3 (See Fig. 4), that is accompanied by a second one involving the $\pi^{*}{ }_{\mathrm{CC}}$ antibondinginstead of the $\pi^{*} \mathrm{CN}$ antibonding- one. No doubt these interactions play a relatively important role in stabilizing this complex because, owing to the unfavorable orientation of the HB donor with respect to the HB acceptor (both molecules lie in parallel planes $1.3 \AA$ apart) the HB's are rather weak, as reflected in both the distances and the charge densities at the bcp.

The dimer EZ4 is stabilized essentially through an $\mathrm{N}-\mathrm{H} \cdots \mathrm{N} \mathrm{HB}$, but there is also a second weak interaction between the $\sigma_{\mathrm{NH}}$ bonding orbital of the $\mathrm{HB}$ acceptor monomer and the $\pi^{*}{ }_{\mathrm{CC}}$ antibonding orbital of the HB donor monomer, which is reflected in the existence of a bond path between the corresponding NH hydrogen and the $\alpha$ - carbon of the $\mathrm{C}=\mathrm{C}$ bond.

\section{Cooperative effects}

Another question of interest is whether the formation of the cyclic dimer $\mathbf{Z Z 1}$, which is the complex that exhibits the strongest HB's of the whole series of dimers investigated, implies the appearance of internal cooperativity effects, as has been found for the cyclic dimers of

phosphinic acid. ${ }^{22}$ To answer this question we can compare the characteristics of this complex, in which both monomers behave simultaneously as HB donor and HB acceptor, with the ZZ2 dimer, in which only one $\mathrm{N}-\mathrm{H} \cdots \mathrm{N}$ hydrogen bond is formed. It seems evident that cooperativity is not negligible. The charge density at the $\mathrm{NH}^{\cdots} \cdot \mathrm{N}$ bcp is 0.004 au larger in $\mathbf{Z Z 1}$ than in ZZ2 (See Fig. 4) and accordingly the corresponding distance is $0.071 \AA$ shorter (See Fig. 3). Coherently, the charge density at the N-H donor decreases by 0.004 au on going from ZZZ to ZZ1 and the red shift of the N-H stretching frequency (see Table 2) increases by $251 \mathrm{~cm}^{-1}$.

It is also worth noting that the $\mathrm{NH} \cdots \mathrm{N}$ HB in complex EZ3, despite involving the less acidic hydrogen of the amino group, is slightly stronger than that in the EZ2 dimer that involves the most acidic hydrogen of the amino group. Cooperative effects are also behind this strengthenhancement due to the presence in EZ3 of an additional $\mathrm{CH} \cdots \mathrm{N}$ HB.

\section{Conclusions}

The most stable aminoacrylonitrile dimers can be classified according to the nature of the interacting monomers as EE-, EZ- and ZZ-type. The primary factor controlling the relative stability of these dimers is the intrinsic stability of the two monomers intervening in the complex. Taking into account the fact that the $\mathbf{Z}$ monomer is predicted to be ca. $8 \mathrm{~kJ} \mathrm{~mol}^{-1}$ more stable than the $\mathbf{E}$ monomer, we have found the ZZ-type dimers to be more stable than the $\mathbf{E Z}$ - ones and these are more stable than the EE ones. No matter the composition of the dimer, the most stable 
complexes correspond to those in which the HB acceptor is the cyano group. Complexes in which the HB acceptor is the amino group are less stable, both in terms of enthalpies and free energies.

The global minimum, $\mathbf{Z Z 1}$, benefits not only from the enhanced stability of the $\mathbf{Z}$ monomer but also from non-negligible cooperative effects, which are reflected in shorter bond distances, greater charge densities at the bcp, and larger frequency shifts of the N-H donor stretch. The cyclic nature of this $\mathrm{C}_{\mathrm{i}}$-symmetry complex renders it entropically disfavored. Accordingly, the gaps between the global minimum and other local minima of the PES in terms of free energies are significantly smaller than the gaps in terms of enthalpies. The most important consequence is that at temperatures close to the boiling point of aminoacrylonitrile, the presence of dimers in the vapor should be as follows: ZZ1 (90.2\%), ZZ2 (4.2\%), EZ1 (2.8\%), EZ2 (1.8\%) and EZ3 (1\%).

The estimated dimerization enthalpy for aminoacrylonitrile is only slightly smaller than those of carboxylic acids, such as formic, acetic or trifluoroacetic acid. Hence, we may assume that it is very probable that the aminoacrylonitrile vapors should contain a significant amount of dimers.

\section{Acknowledgments}

This work has been partially supported by the DGI Project No. BQU2003-00894, and by the COST Action D26/014/03 project. A generous allocation of computational time at the CCC of the Universidad Autónoma de Madrid is also gratefully acknowledged. J.-C. G. thanks the PCMI (INSU-CNRS) for financial support.

\section{References and Footnotes}

1. Mann, A. P. C.; Williams, D. A. Nature 1980, 283, 721.

2. Ungerechts, H.; Warmsley, C. M.; Winnewisser, G. Astronomy \& Astrophys. 1980, 88, 259.

3. Bockelee-Morvan, D.; Lis, D. C.; Wink, J. E.; Despois, D.; Crovisier, J.; Bachiller, R.; Benford, D. J.; Biver, N.; Colom, P.; Davies, J. K.; Gerard, E.; Germain, B.; Houde, M.; Mehringer, D.; Moreno, R.; Paubert, G.; Phillips, T. G.; Rauer, H. Astronomy \& Astrophys. 2000, 353, 1101.

4. Kunde, V. G.; Aikin, A. C.; Hanel, R. A.; Jennings, D. E.; Maguire, W. C.; Samuelson, R. E. Nature 1981, 292, 686.

5. Coustenis, A.; Encrenaz, T.; Bézard, B.; Bjoraker, B.; Graner, G.; Dang-Nhu, G.; Arié, E. Icarus 1993, 102, 240.

6. Sanchez, R. A.; Ferris, J. P.; Orgel, L. E. Science 1966, 154, 784.

7. Ferris, J. P.; Sanchez, R. A.; Orgel, L. E. J. Mol. Biol. 1968, 33, 693.

8. Toupance, G.; Raulin, F.; Buvet, R. Origins of Life 1975, 6, 83. 
9. Orgel, L. E. Orig. Life \& Evol. Biosph. 2002, 32, 279.

10. Fow, S. W.; Dose, K. Molecular Evolution and the Origin of Life; Marcel Dekker Inc.: New York, 1977.

11. Solomon, P. M. Physics Today, 26, 32.

12. Marten, A.; Courtin, R.; Gautier, D.; Lacombe, A. Icarus 1980, 41, 410.

13. Xiang, Y.-B.; Drenkard, S.; Baumann, K.; Hickey, D.; Eschenmoser, A. Helv. Chim. Acta 1994, 77, 2209.

14. Guillemin, J.-C.; Breneman, C. M.; Josepha, J. C.; Ferris, J. P. Chemistry Eur. J. 1998, 4, 1074.

15. Benidar, A.; Guillemin, J.-C.; Mó, O.; Yáñez, M. J. Phys. Cem. A 2005 (accepted for publication).

16. Curtiss, L. A.; Blander, M. Chem. Rev. 1988, 88, 871.

17. Chao, J.; Zwolinski, J. J. Phys. Chem. Ref. Data 1978, 7, 363.

18. Nelson, Jr. D. D.; Fraser, G. T. ; Klemperer, W. Science 1987, 238, 1670

19. Mó, O.; Yáñez, M.; Elguero, J. J. Chem. Phys. 1992, 97, 6628.

20. Mó, O.; Yáñez, M.; Elguero, J. J. Mol. Struct. (Theochem) 1994, 120, 73.

21. Gonzalez, L.; Mó, O.; Yáñez, M.; Elguero, J. J. Mol. Struct. (Theochem) 1996, 371, 1.

22. Mó, O.; Yáñez, M.; Elguero, J. J. Chem. Phys. 1997, 107, 3592.

23. Gonzalez, L.; Mó, O.; Yáñez, M.; Elguero, J. J. Chem. Phys. 1998, 109, 2685.

24. González, L.; Mó, O.; Yáñez, M.; Elguero, J. ChemPhysChem 2001, 7, 465.

25. Mó, O.; Yáñez, M.; González, L.; Elguero, J. ChemPhysChem 2001, 465.

26. Becke, A. D. J. Chem. Phys. 1993, 98, 1372.

27. Lee, C.; Yang, W.; Parr, R. G. Phys. Rev. B: Condens. Matter 1988, 37, 785.

28. Gonzalez, L.; Mó, O.; Yáñez, M. J. Comput. Chem. 1997, 18, 1124.

29. Gonzalez, L.; Mó, O.; Yáñez, M. J. Phys. Chem. A 1997, 101, 9710.

30. Gonzalez, L.; Mó, O.; Yáñez, M. J. Chem. Phys. 1998, 109, 139.

31. Frisch, M. J.; Trucks, G. W.; Schlegel, H. B.; Scuseria, G. E.; Robb, M. A.; Cheeseman, J. R.; Zakrzewski, V. G.; J. A. Montgomery, J.; Stratmann, R. E.; Burant, J. C.; Dapprich, S.; Millam, J. M.; Daniels, A. D.; Kudin, K. N.; Strain, M. C.; Farkas, O.; Tomasi, J.; Barone, V.; Cossi, M.; Cammi, R.; Mennucci, B.; Pomelli, C.; Adamo, C.; Clifford, S.; Ochterski, J.; Petersson, G. A.; Ayala, P. Y.; Cui, Q.; Morokuma, K.; Malick, D. K.; Rabuck, A. D.; Raghavachari, K.; Foresman, J. B.; Cioslowski, J.; Ortiz, J. V.; Stefanov, B. B.; Liu, G.; Liashenko, A.; Piskorz, P.; Komaromi, I.; Gomperts, R.; Martin, R. L.; Fox, D. J.; Keith, T.; Al-Laham, M. A.; Peng, C. Y.; Nanayakkara, A.; Gonzalez, C.; Challacombe, M.; Gill, P. M. W.; Johnson, B.; Chen, W.; Wong, M. W.; Andres, J. L.; Gonzalez, C.; Head-Gordon, M.; Replogle, E. S.; Pople, J. A. In; Gaussian98, Revised A3 Ed.; Gaussian, Inc.: Pittsburgh PA, 1999.

32. Frisch, M. J.; Trucks, G. W.; Schlegel, H. B.; Scuseria, G. E.; Robb, M. A.; Cheeseman, J. R.; Zakrzewski, V. G.; J. A. Montgomery, J.; Vreven, T.; Kudin, N.; Burant, J. C.; Millam, J. M.; Iyengar, S. S.; Tomasi, J.; Barone, V.; Mennucci, B.; Cossi, M.; Scalmani, G.; Rega, 
N.; Petersson, G. A.; Nakatsuji, H.; Hada, M.; Ehara, M.; Toyota, K.; Fukuda, R.; Hasegawa, J.; Ishida, M.; Nakajima, T.; Honda, Y.; Kitao, O.; Adamo, C.; Jaramillo, J.; Gomperts, R.; Stratmann, R. E.; Yazyev, O.; Austin, J.; Cammi, R.; Pomelli, C.; Ochterski, J. C.; Ayala, P. Y.; Morokuma, K.; Voth, G. A.; Salvador, P.; Dannenberg, J. J.; Zakrzewski, G.; Dapprich, S.; Daniels, A. D.; Strain, M. C.; Farkas, O.; Malick, D. K.; Rabuck, A. D.; Raghavachari, K.; Foresman, J. B.; Ortiz, J. V.; Cui, Q.; Baboul, A. G.; Clifford, S.; Cioslowski, J.; Stefanov, B. B.; Liu, G.; Liashenko, A.; Piskorz, P.; Komaromi, I.; Martin, R. L.; Fox, D. J.; Keith, T.; Al-Laham, M. A.; Peng, C. Y.; Nanayakkara, A.; Challacombe, M.; Gill, P. M. W.; Johnson, B.; Chen, W.; Wong, M. W.; Gonzalez, C.; Pople, J. A. In; Gaussian98, Revision B.05 Ed.; Gaussian, Inc.: Pittsburgh PA, 2003.

33. Bader, R. F. W. Atoms in Molecules. A Quantum Theory; Oxford University Press: Oxford, 1990.

34. Bader, R. F. W.; Cheeseman, J. R. In; AIMPAC Ed., 2000.

35. Reed, A. E.; Curtiss, L. A.; Weinhold, F. Chem. Rev. 1988, 88, 899. 